\title{
SCIENTIFIC REP \\ Depletion of potassium and sodium in mantles of Mars, Moon and Vesta by core formation
}

Received: 8 January 2018

Accepted: 24 April 2018

Published online: 04 May 2018

\author{
E. S. Steenstra ${ }^{1}$, N. Agmon ${ }^{1}$, J. Berndt ${ }^{2}$, S. Klemme ${ }^{2}$, S. Matveev ${ }^{3}$ \& W. van Westrenen ${ }^{1}$
}

The depletions of potassium $(\mathrm{K})$ and sodium $(\mathrm{Na})$ in samples from planetary interiors have long been considered as primary evidence for their volatile behavior during planetary formation processes. Here, we use high-pressure experiments combined with laser ablation analyses to measure the sulfidesilicate and metal-silicate partitioning of $\mathrm{K}$ and $\mathrm{Na}$ at high pressure $(P)$ - temperature $(T)$ and find that their partitioning into metal strongly increases with temperature. Results indicate that the observed Vestan and Martian mantle $\mathrm{K}$ and $\mathrm{Na}$ depletions can reflect sequestration into their sulfur-rich cores in addition to their volatility during formation of Mars and Vesta. This suggests that alkali depletions are not affected solely by incomplete condensation or partial volatilization during planetary formation and differentiation, but additionally or even primarily reflect the thermal and chemical conditions during core formation. Core sequestration is also significant for the Moon, but lunar mantle depletions of $\mathrm{K}$ and $\mathrm{Na}$ cannot be reconciled by core formation only. This supports the hypothesis that measured isotopic fractionations of $K$ in lunar samples represent incomplete condensation or extensive volatile loss during the Moon-forming giant impact.

The alkali elements, including potassium $(\mathrm{K})$ and sodium $(\mathrm{Na})$, are moderately volatile elements and their measured depletions in the mantles of Vesta, Mars and the Moon are considered a cornerstone for planet formation models $s^{1-4}$. K and Na depletions in meteoritic samples from Mars and asteroid (4) Vesta are one of the major lines of evidence to argue for extensive volatile loss during their formation or subsequent magmatic events ${ }^{3,5}$. Similarly, the depletions of $\mathrm{K}$ and $\mathrm{Na}$ in the lunar mantle relative to the bulk silicate Earth (BSE) are interpreted as primary evidence for extensive volatile loss during the Moon-forming giant impact event ${ }^{2-5}$. In addition to its relevance to constraining planetary budgets of volatile elements, the abundance and distribution of the heat producing element $\mathrm{K}$ in planets have profound implications for the thermal evolution of planetary bodies including the Earth and Mars $^{6-9}$. For example, $\mathrm{K}$ abundance and distribution may determine the onset and duration of core dynamos $^{6,8}$ as well as plate tectonic evolution on Earth ${ }^{7}$.

To date, the metallic cores that segregated from the silicate mantle during early planetary evolution processes in Mars, the Moon and Vesta have generally not been considered as important alternative or additional reservoirs for alkalis. It has long been recognized, through studies of iron meteorites and laboratory experiments, that under specific conditions alkali elements may partition into Fe-rich metals ${ }^{6,10-17}$, but the specific effects of temperature and composition that may affect metal-silicate partitioning of $\mathrm{K}$ and $\mathrm{Na}$ are not well constrained. Previous studies were hampered by a range of analytical challenges including loss of alkalis during polishing with lubricants, relatively high detection limits of electron microprobe analysis (EMPA), "smearing" effects during sample preparation (leading to artificial enrichment of alkalis in metals by smearing alkali-rich silicate materials onto their surface) and simultaneous variation of multiple variables, prohibiting isolation of the individual parameters that affect K metal-silicate partitioning. Only two studies determined the sulfide-silicate partitioning behavior of $\mathrm{Na}^{11,17}$. As a result, it is hard to quantify to which extent these elements may have partitioned into the cores of differentiated planets, moons, and asteroids. Here, we present the first sulfide-silicate and metal-silicate partition coefficients for $\mathrm{K}$ and $\mathrm{Na}$ at high temperature and high pressure using a newly set up high-precision LA-ICP-MS (Laser Ablation Inductively Coupled Plasma Mass Spectrometry) technique, specifically constraining the individual effects of temperature and composition on $\mathrm{K}$ and $\mathrm{Na}$ partitioning. We use these results to assess whether $\mathrm{K}$ and Na may have (partly) partitioned into the Vestan, Marian and/or lunar core.

${ }^{1}$ Faculty of Science, VU Amsterdam, Amsterdam, The Netherlands. ${ }^{2}$ Institute of Mineralogy, University of Münster, Münster, Germany. ${ }^{3}$ Faculty of Geosciences, Utrecht University, Utrecht, The Netherlands. Correspondence and requests for materials should be addressed to E.S.S. (email: e.s.steenstra@vu.nl) 


\begin{tabular}{|l|l|l|l|l|l|l|}
\hline Run \# & T (K) & Time $(\mathbf{m i n})$ & Composition & $\mathbf{n b o} / \mathbf{t}^{\mathbf{a}}$ & $\log \boldsymbol{K}_{\mathbf{K}}$ & $\log \boldsymbol{K}_{\mathrm{Na}}$ \\
\hline GGK1 & 1683 & 60 & Basalt + Fe & 1.95 & $-2.93(21)^{\mathrm{b}}$ & b.d.l. $^{\mathrm{c}}$ \\
\hline GGK2 & 1783 & 60 & Basalt + Fe & 2.24 & $-2.89(34)$ & b.d.l. \\
\hline GGK3 & 1883 & 60 & Basalt + Fe & 2.23 & $-2.40(10)$ & b.d.l. \\
\hline GGK4 & 1683 & 60 & Basalt + FeS & 1.25 & $-3.04(9)$ & $-3.12(9)$ \\
\hline GGK5b & 1783 & 30 & Basalt + FeS & 1.60 & $-2.61(5)$ & $-2.51(15)$ \\
\hline GGK6 & 1883 & 60 & Basalt + FeS & 1.54 & $-2.25(9)$ & $-2.22(18)$ \\
\hline GGK7 & 1683 & 60 & Basalt + Fe $-17 \% \mathrm{Si}$ & 0.63 & $-3.95(9)^{\mathrm{b}}$ & b.d.l. \\
\hline GGK8 & 1783 & 60 & Basalt + Fe $-17 \% \mathrm{Si}$ & 1.05 & $-4.21(9)^{\mathrm{b}}$ & b.d.l. \\
\hline GGK9 & 1883 & 60 & Basalt + Fe $-17 \% \mathrm{Si}$ & 1.07 & $-4.48(29)^{\mathrm{b}}$ & b.d.l. \\
\hline LGK1b & 1883 & 15 & Granite + FeS & 0.40 & $-4.25(3)$ & $-2.89(9)^{\mathrm{b}}$ \\
\hline LGK2 & 1683 & 30 & Granite + FeS & 0.07 & $-4.08(8)$ & n.d. ${ }^{\text {b }}$ \\
\hline LGK3b & 1783 & 15 & Granite + FeS & 0.12 & $-4.23(4)$ & b.d.l. \\
\hline LGK4b & 1683 & 60 & Granite + Fe & 0.08 & $-3.21(6)$ & b.d.l. \\
\hline LGK5 & 1783 & 60 & Granite + Fe & 0.35 & $-3.06(24)$ & b.d.l. \\
\hline LGK6 & 1883 & 60 & Granite + Fe & 0.53 & $-2.84(18)$ & b.d.l. \\
\hline
\end{tabular}

Table 1. Experimental run conditions and measured equilibrium constants for $\mathrm{K}$ and $\mathrm{Na}$ at $1 \mathrm{GPa}$. All values are based on LA-ICP-MS measurements of both metal and silicate, except for run GGK6 (Supplementary Information). Numbers in brackets are errors in terms of least digits cited and calculated through simple error propagation while assuming 2 standard errors for EPMA and LA-ICP-MS analyses. ${ }^{a}$ nbo/t $=[2 \times \mathrm{O}-4 \times \mathrm{T}] / \mathrm{T}$ where $[2 \times \mathrm{O}-4 \mathrm{~T}]$ refers to the number of non-bridging oxygen ions and $\mathrm{T}$ represents the number of tetrahedrally coordinated cations ${ }^{28}$ b $C l o s e$ to or below detection limit ${ }^{\mathrm{c} B e l o w}$ detection limit ${ }^{\mathrm{d}}$ Not determined.

\section{Results}

High pressure-temperature experiments. Experiments were performed in graphite-lined Pt capsules at a constant pressure of $1 \mathrm{GPa}$ and temperatures of $1683-1883 \mathrm{~K}$ to determine metal-silicate and sulfide-silicate partition coefficients for $\mathrm{K}$ and $\mathrm{Na}$ (Table 1). Starting compositions consisted of synthetic analogues of a primitive basaltic glass and a rhyolitic composition combined with Fe-C, Fe-C-Si or FeS metals. After careful dry polishing $^{6}$, samples were analyzed with electron microprobes (EMPA) at Utrecht University and Münster University and using LA-ICP-MS at Münster University (Supplementary Information). Run products were characterized by well segregated $\mathrm{Fe}(-\mathrm{S})$ blobs in a quenched silicate melt (Fig. 1). Experimental run products of the basalt series quenched occasionally to a heterogeneous spinifex-textured glass, whereas the granitic composition always quenched to a glass.

The use of LA-ICP-MS enables significantly more reliable determinations of $\mathrm{K}$ and $\mathrm{Na}$ abundances in the metal and sulfide phases, as potential "smearing" of $\mathrm{K}$ and $\mathrm{Na}$ from the coexisting silicate onto the metal can be isolated effectively from the metal signal itself (Fig. 1). For several samples, independent of K content, smearing effects resulted in EPMA significantly overestimating the amount of $\mathrm{K}$, highlighting the necessity of using LA-ICP-MS (Fig. S4, Supplementary Information).

Besides problems with the use of oil-based lubricants during polishing, these "smearing" effects may explain the significant discrepancies between earlier studies. K and Na abundances measured by LA-ICP-MS are not affected by secondary fluorescence and the large beam-size $(110 \mu \mathrm{m})$ is expected to yield a better average of the metallic composition given the heterogeneous distribution of $\mathrm{K}$ and $\mathrm{Na}$ in both the metal and silicate melt that is common in these types of experiments (Fig. S1, Supplementary Information).

Metal-silicate and sulfide-silicate partitioning of $\mathrm{K}$ and $\mathrm{Na}$. Partitioning of monovalent $\mathrm{K}$ and $\mathrm{Na}$ between sulfide/metal and silicate can be described with the following exchange reactions ${ }^{14}$ :

$$
\begin{gathered}
0.5 \mathrm{Fe}_{(\text {metal })}+0.5 \mathrm{~K}_{2} \mathrm{O}_{\text {(silicate) }} \leftrightarrow \mathrm{K}_{(\text {metal })}+0.5 \mathrm{FeO}_{\text {(silicate) }} \\
0.5 \mathrm{Fe}_{(\text {metal })}+0.5 \mathrm{Na}_{2} \mathrm{O}_{(\text {silicate })} \leftrightarrow \mathrm{Na}_{(\text {metal })}+0.5 \mathrm{FeO}_{(\text {silicate })}
\end{gathered}
$$

where the equilibrium constants $(K)$ of the latter reactions can be expressed as:

$$
\begin{gathered}
\log K_{\mathrm{K}}=\log \frac{\left(\mathrm{x}_{\mathrm{FeO}}^{\text {silicate }}\right)^{0.5} \cdot\left(\mathrm{x}_{\mathrm{K}}^{\text {metal or sulfide }}\right)}{\left(\mathrm{x}_{\mathrm{KO} \mathrm{O}_{0.5}}^{\text {silicate }}\right) \cdot\left(\mathrm{x}_{\mathrm{Fe}}^{\text {metal or sulfide }}\right)^{0.5}}+\log \frac{\left(\gamma_{\mathrm{K}}^{\text {metal or sulfide }}\right)}{\left(\gamma_{\mathrm{Fe}}^{\text {metal or sulfide }}\right)^{0.5}}+\log \frac{\left(\gamma_{\mathrm{FeO}}^{\text {silicate }}\right)^{0.5}}{\left(\gamma_{\mathrm{KO}}^{\text {silicate }}\right)} \\
\log K_{\mathrm{Na}}=\log \frac{\left(\mathrm{x}_{\mathrm{FeO}}^{\text {silicate }}\right)^{0.5} \cdot\left(\mathrm{x}_{\mathrm{Na}}^{\text {metal or sulfide }}\right)}{\left(\mathrm{x}_{\mathrm{NaO}}^{\text {silicate }}\right) \cdot\left(\mathrm{x}_{\mathrm{Fe}}^{\text {metal or sulfide }}\right)^{0.5}}+\log \frac{\left(\gamma_{\mathrm{Na}}^{\text {metal or sulfide }}\right)}{\left(\gamma_{\mathrm{Fe}}^{\text {metal or sulfide }}\right)^{0.5}}+\log \frac{\left(\gamma_{\mathrm{FeO}}^{\text {silicate }}\right)^{0.5}}{\left(\gamma_{\mathrm{NaO}}^{\text {silicate }}\right)}
\end{gathered}
$$

where the first term on the right-hand side is the exchange coefficient or $K_{\mathrm{K}}^{\mathrm{D}}, K_{\mathrm{Na}}^{\mathrm{D}}$ and x defined as their molar fraction in the metal or silicate. The second and third terms relate to their activity coefficients $(\gamma)$ in the metal, sulfide or silicate melt ${ }^{18}$. The variability in $\gamma_{\mathrm{FeO}}^{\text {silicate }}$ was modeled as a function of silicate melt composition ${ }^{19}$ and 


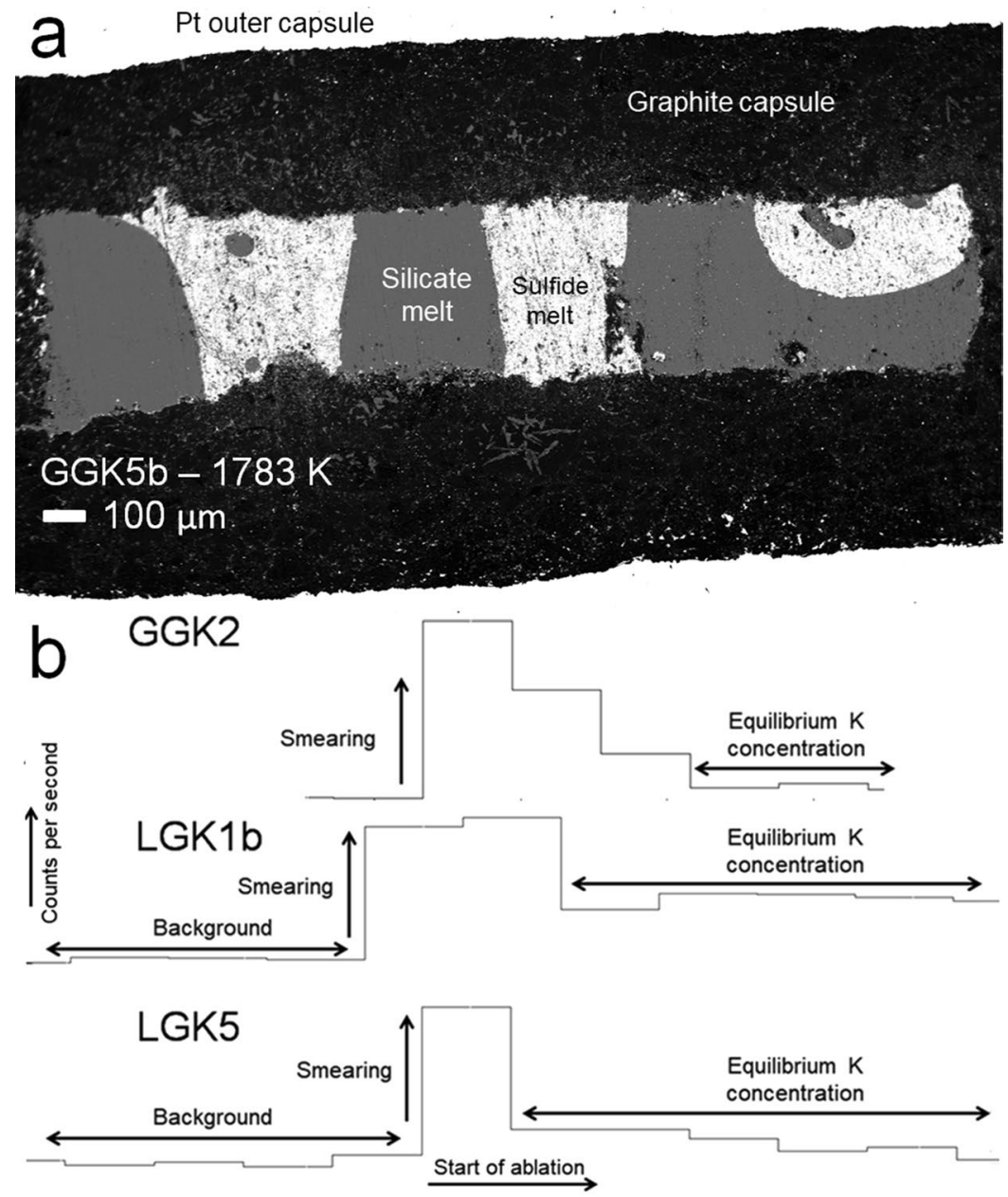

Figure 1. (a) Backscattered electron image of typical run product (experiment GGK5b performed at 1783 K, Table 1) (b) Example LA-ICP-MS GLITTER ${ }^{\circledR}$ profiles for K in selected sulfides and metals. High signal intensities in the initial ablation reflect the much higher abundances of $\mathrm{K}$ on the sulfide or metal surface in some runs due to smearing. The stable plateau after this initial peak reflects the actual concentration of $\mathrm{K}$ in the sulfide or metal phase, which is far lower than the initial peak.

$\gamma_{\mathrm{Fe}}^{\text {metal }}$ was calculated using the online metal activity calculator ${ }^{18}$ or with a thermodynamic model specifically for $\mathrm{Fe}-\mathrm{S}$ alloys in the case of S-bearing iron phase ${ }^{20}$ (Supplementary Information). Application of Eqs $(3,4)$ requires constraints on the activity coefficients of $\mathrm{K}$ and $\mathrm{Na}$ in the metallic $\left(\gamma_{\mathrm{Na}, \mathrm{K}}^{\text {metal sulfide }}\right)$ and silicate melts $\left(\gamma_{\mathrm{KO}_{0.5}, \mathrm{NaO}_{0.5}}^{\text {siliate }}\right)$. As there are no predictive models for $\gamma_{\mathrm{KO}}^{\text {silicate }} \mathrm{NaO}_{0.5}$ as a function of silicate melt composition, we assume ideal behavior $^{14}$. The variability of activity coefficients of $\mathrm{K}$ and $\mathrm{Na}$ as a function of $\mathrm{S}$ and $\mathrm{Si}$ in the metal phase were determined using a thermodynamic approach discussed in the next section.

Effects of metal composition and temperature on $\mathrm{K}$ and $\mathrm{Na}$ partitioning. To assess the effects of $\mathrm{S}$ and $\mathrm{Si}$ in the metal or sulfide on sulfide/metal-silicate partitioning, new interaction coefficients were derived using a thermodynamic approach (Supplementary Information). It was found that $\mathrm{K}$ and $\mathrm{Na}$ behave chalcophile, in agreement with previous studies $6,11,12,16,17$. The addition of Si to the metal has an opposite effect, resulting in a substantial decrease of their siderophile behavior, in agreement with the negative effects of Si on metal-silicate partitioning of virtually all siderophile elements ${ }^{21,22}$. Blanchard et al. ${ }^{14}$ recently found no clear effects of $S$ in metal on the metal-silicate partitioning of $\mathrm{K}$ at $49-81 \mathrm{GPa}$ and $3600-4100 \mathrm{~K}$. This discrepancy could be related to currently unconstrained effects of temperature and/or pressure on the interaction coefficient between $\mathrm{K}$ and $\mathrm{S}$ in $\mathrm{Fe}-\mathrm{S}$ bearing alloys. Such effects could be substantial. For example, Wang et al. ${ }^{23}$ found that $\mathrm{Cd}$, In and $\mathrm{Zn}$ behave chalcophile at 15 and $20 \mathrm{GPa}$, whereas Wood et al. ${ }^{24}$ reported chalcophobic behavior of these elements at low pressure.

Previous studies found that Fe-S alloys at our experimental conditions should contain up to $1.5 \mathrm{wt} . \%$ of $\mathrm{O}^{25-27}$, which could affect the partitioning of $\mathrm{K}$ and $\mathrm{Na}$. We find that in our experiments, the abundance of $\mathrm{O}$ is highly correlated with $\mathrm{K}$, resulting in $\mathrm{O}$ concentrations (up to $\sim 5 \mathrm{wt} . \%$ ) that far exceed the solubility of O predicted for $\mathrm{K}$-free $\mathrm{Fe}-\mathrm{S}$ alloys at the redox conditions of our experiments $(1.44 \mathrm{wt} . \%)^{25,26}$ (Fig. S8, Supplementary Information). This suggest that $\mathrm{O}$ "follows" $\mathrm{K}$ in the sulfide, rather than directly increasing $\mathrm{D}(\mathrm{K})^{17}$ values due to its effects on $\mathrm{FeO}$ activities in sulfide melts ${ }^{25-27}$, as the $\mathrm{O}$ concentrations at very low $\mathrm{K}$ contents are within error 

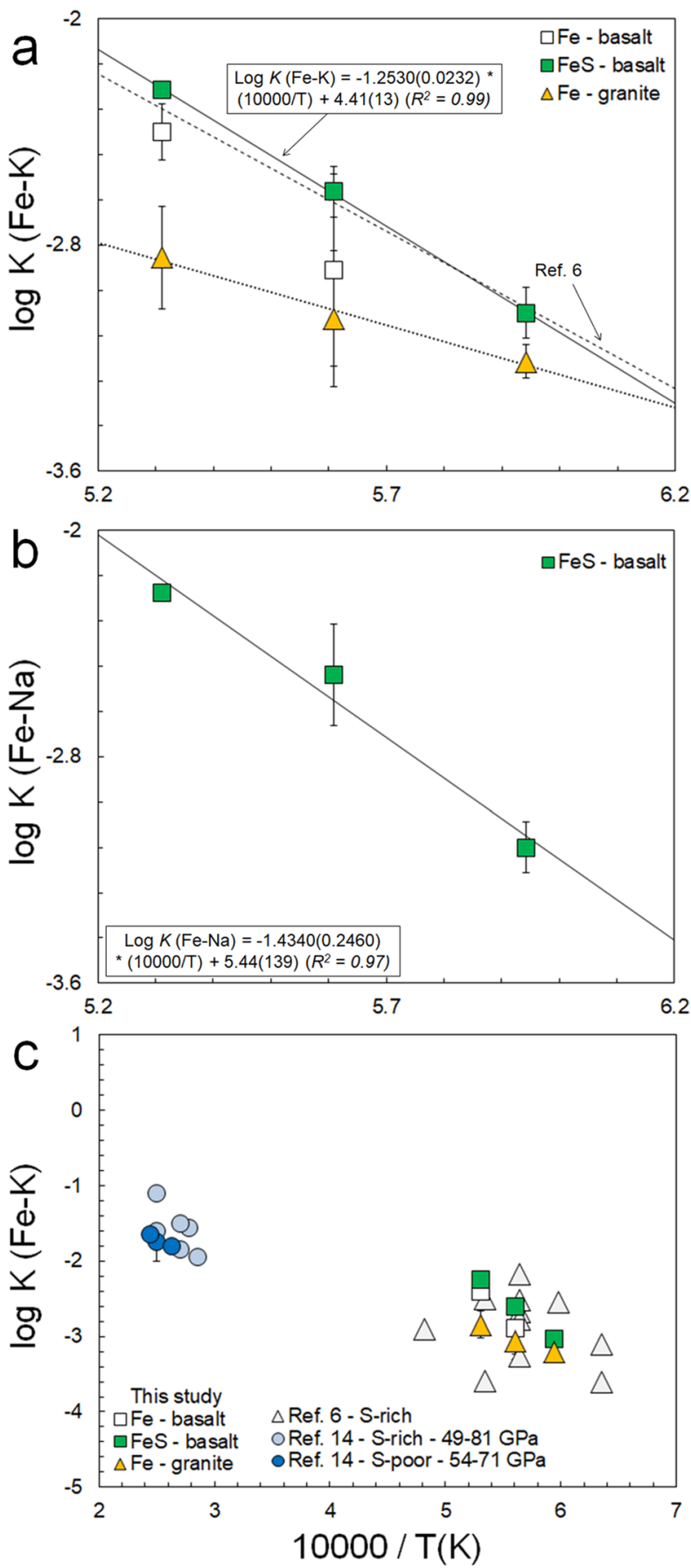

Figure 2. (a-c) Sulfide-silicate and metal-silicate equilibrium constants for $\mathrm{K}$ and $\mathrm{Na}$ as a function of temperature (in Kelvin) from this study, Murthy et al. ${ }^{6}$ and Blanchard et al. ${ }^{14}$. Solid line in (a,b) are the best-fit dependency for the FeS - basalt data. Errors represent 2 standard errors and were calculated by simple error propagation.

with that of the predicted $\mathrm{O}$ contents for K-free sulfides. Using our derived interaction parameters, we corrected for any variability in the $\log K_{\mathrm{K}, \mathrm{Na}}$ due to different metal compositions (Supplementary Information). Given the geochemical highly similar behavior of $\mathrm{K}$ and $\mathrm{Na}$, we assume that the effects of $\mathrm{S}$ on $\mathrm{Na}$ are the same as that for $\mathrm{K}^{11,17}$.

Figure 2 shows our measured sulfide-silicate and metal-silicate $\log K_{\mathrm{K}, \mathrm{Na}}$ values. We find a clear and strong increase of both $\mathrm{K}$ and $\mathrm{Na}$ partitioning with temperature. The magnitude of the effect found for the experiments with a basaltic silicate melt are in good agreement with two previous studies ${ }^{6,12}$, but much larger than reported in other studies ${ }^{14,16}$. Corgne et al. ${ }^{16}$ found no effect of temperature on partitioning of $\mathrm{K}$, which could be related to the use of single capsules in the majority of their experiments, resulting in variable losses of $\mathrm{K}$. The less pronounced effects of temperature within the granitic series are likely related to the high and variable degrees of melt 
polymerization in that set of experiments (Supplementary Information). Comparing our new sulfide-silicate partitioning data with the recently reported diamond anvil cell data of Blanchard et al. ${ }^{14}$ confirms our hypothesis that increasing temperature (and possibly pressure) significantly increases the sulfide/metal-silicate partition coefficient of $\mathrm{K}$. We note that the equilibrium constants from Blanchard et al ${ }^{14}$ derived for $<10 \mathrm{wt} . \% \mathrm{~S}$ bearing alloys are likely lower limits relative to our sulfide-silicate partitioning data if S affects K partitioning at these very high pressures.

The dependencies of $\log K_{\mathrm{K}, \mathrm{Na}}$ on temperature are well quantified using the following relationships derived for Fe-S experiments:

$$
\begin{gathered}
\log K_{\mathrm{K}}=4.41(13)+\frac{-12530(235)}{T(K)} \\
\log K_{\mathrm{Na}}=5.44(139)+\frac{-14340(2460)}{T(K)}
\end{gathered}
$$

Pressure may also affect alkali partitioning behavior, but most previous studies found no significant effects of pressure ${ }^{6,12,15}$ (Supplementary Information). Blanchard et al. ${ }^{14}$ reported a pressure term for $\log K_{\mathrm{K}}$ derived over a $70 \mathrm{GPa}$ range. If this term is indeed correct, extrapolation of our $1 \mathrm{GPa}$ experiments to the core-mantle boundary of Mars $(\sim 20 \mathrm{GPa})$, would only result in an increase of $\sim 0.5 \mathrm{in} \log K_{\mathrm{K}}$. We therefore consider our data to be appropriate for core formation scenarios in bodies ranging from asteroid to at least Mars sized. Alternatively, one can consider our results to be a lower limit.

It has been suggested that polymerization of silicate melts affects the sulfide-silicate and metal-silicate partitioning of $\mathrm{K}$ and $\mathrm{Na}^{6,11}$. Consideration of $\log K_{\mathrm{K}}$ versus $\mathrm{nbo} / \mathrm{t}$, a single term proxy for the degree of silicate melt polymerization $^{28}$, suggests the iron-loving behavior of $\mathrm{K}$ may be affected at the highest degrees of melt polymerization (low nbo/t, see Supplementary Information). We find no consistent variation of $\log \log K_{\mathrm{K}}$ within the range of high nbo/t values relevant for planetary mantles ( 2.5-3), consistent with previous studies ${ }^{6,12,29}$. Given the geochemically similar behavior of $\mathrm{K}$ and $\mathrm{Na}$, it is likely $\mathrm{Na}$ will behave similarly ${ }^{11}$. We therefore apply our results for the basalt-series for modeling core formation in Vesta, Mars and the Moon.

Assessment of $\mathrm{K}$ and $\mathrm{Na}$ contents in planetary cores. Many previous studies focused on geochemical and geophysical properties of Mars and Vesta reported high sulfur (S) contents for both of their cores, ranging between $10-25$ wt. $\%^{30-35}$. High core $S$ contents are inferred from the high abundance of $S$ in their most plausible building blocks and meteoritic samples from these bodies ${ }^{31,33,36-38}$, the existence of core dynamos in their early history ${ }^{39,40}$, depletion patterns of refractory siderophile elements $\mathrm{s}^{30,41,42}$ as well as geophysical constraints such as their moment of inertia and corresponding core densities ${ }^{34,43}$.

Our new metal-silicate partitioning models for $\mathrm{K}$ and $\mathrm{Na}$ (Eqs 5, 6) suggest that the measured depletions of $\mathrm{K}$ and $\mathrm{Na}$ in Martian mantle samples can be completely explained by their partitioning into a $25 \mathrm{wt}$.\% S-bearing Martian core at temperatures of $\sim 2560 \pm 60 \mathrm{~K}$ and $\sim 2300 \pm 200 \mathrm{~K}$, respectively. This is increased to $\sim 2875 \pm 75 \mathrm{~K}$ and $\sim 2600 \pm 250 \mathrm{~K}$ for the lower limit of current S contents of the Martian core (10 wt.\%). These temperature estimates are in or within $<400 \mathrm{~K}$ of the range of the temperatures previously proposed for Martian core-mantle differentiation based on non-volatile siderophile element depletions in Martian meteorites ${ }^{41,42}$. Global melting of Mars, possibly extending to the core-mantle boundary, is also supported by the estimated volume of the Martian crust and from the existence of two geochemically distinct source regions required for Martian meteorite genesis $^{44}$. It is also in agreement with the inferred early accretion of Mars from Hf-W-Th isotopic evidence, during which radiogenic heating of ${ }^{26} \mathrm{Al}$ decay would already provide sufficient heat to produce a global Martian magma ocean $^{45,46}$ (Supplementary Information).

The Vestan mantle depletions of $\mathrm{K}$ and $\mathrm{Na}$ can be fully explained by core formation depletion at temperatures exceeding $\sim 2025 \pm 25 \mathrm{~K}$ for $\mathrm{K}$ and $\sim 2370 \pm 170 \mathrm{~K}$ for Na, assuming a Vestan core with 25 wt.\% S (Fig. 3). For a Vestan core with $10 \mathrm{wt} . \% \mathrm{~S}$, temperatures have to be increased to $\sim 2300 \pm 25 \mathrm{~K}$ and $2650 \pm 250 \mathrm{~K}$ to explain all mantle depletion by core segregation, respectively. Such temperatures are fully consistent with the global melting of Vesta implied from numerical thermal evolution models in conjunction with the very early accretion of Vesta in the early solar system when ${ }^{26} \mathrm{Al}$ was still abundant ${ }^{47-49}$, homogeneous oxygen isotopic signatures of meteoritic samples from Vesta ${ }^{50,51}$ and siderophile element depletions ${ }^{30,52}$ (Supplementary Information). Such high temperatures would also reproduce an iron isotopic composition of the Vestan mantle that would be consistent with Vesta's chondritic nature ${ }^{53-57}$.

The temperatures at which the Vestan and Martian $\mathrm{K}$ and Na mantle depletions would be fully explained with core formation only are higher than core formation temperatures previously inferred from refractory siderophile element depletions ${ }^{30,41,42,52,58}$. In the Supplementary Information section, we show that refractory siderophile element depletions can also be reconciled with core formation at the higher temperatures required for explaining all alkali depletions, because metal-silicate partition coefficients for refractory siderophile elements are mainly a function of oxygen fugacity, and to a lesser extent core composition in this case ${ }^{30}$. In case of Mars, the higher temperatures would imply whole Mars-melting. This does not agree with thermal constraints on Martian differentiation derived from siderophile element depletions in Martian meteorites that suggest only partial melting of Mars during core formation ${ }^{41,42,58,59}$. It is therefore likely that the higher core formation temperatures derived here indicate that core formation depletion is not the only process depleting $\mathrm{K}$ and $\mathrm{Na}$ during differentiation of Mars. This is further substantiated by other geochemical lines of evidence discussed later in this section.

Our data show that at temperatures and compositions needed to explain non-volatile element mantle depletions in both Mars and Vesta, alkalis also sequester into their cores in significant proportions. Assuming the 

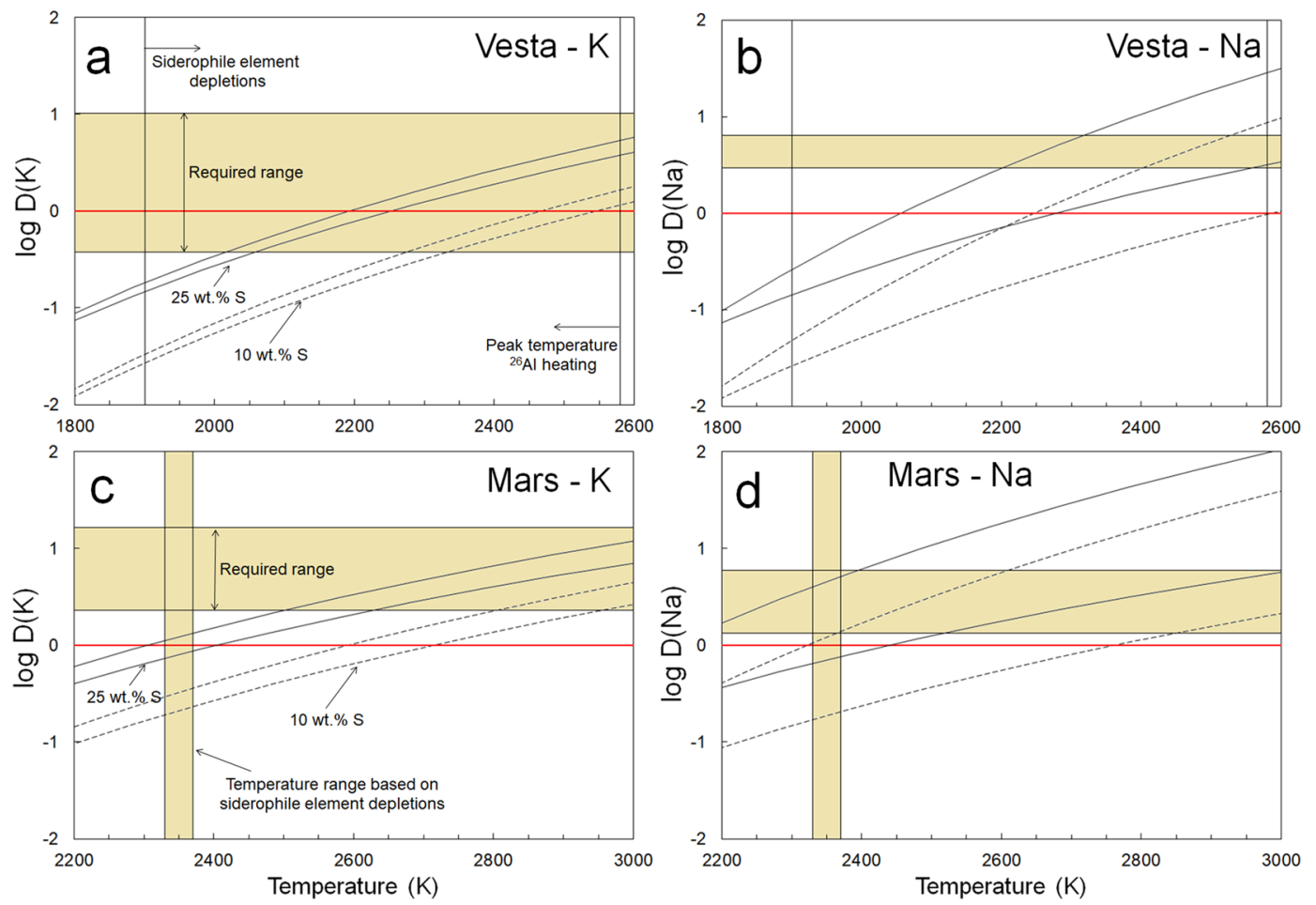

Figure 3. (a,b) Calculated $\mathrm{K}$ and Na partition coefficient ranges for asteroid Vesta, assuming the formation of a 20 to 30 mass \% core at $-2.2 \pm 0.2 \log$ units below the iron-wüstite buffer ${ }^{30,52,83}$, (c,d) Comparable calculations for Mars, assuming the formation of a 20 to 25 mass\% core at $-1.25 \pm 0.25 \log$ units below the iron-wüstite buffer $^{34,41-43}$, for different core sulfur abundances. Ranges include propagated errors on temperature terms. Plotted for reference are the inferred peak temperature due to radiogenic decay of ${ }^{26} \mathrm{Al}$ for Vesta ${ }^{49}$ and core formation temperatures inferred from siderophile element depletions for both bodies ${ }^{30,41,42,52}$. Data sources used to calculate observed alkali element depletions in Mars and Vesta are listed in the Supplementary Materials file. Red line in bold marks the transition from lithophile to siderophile behavior $(\log D=0)$.

minimal partition coefficients of $\mathrm{K}$ and $\mathrm{Na}$ required to fully explain their Martian mantle depletions, at least $\sim 7250 \mathrm{ppm} \mathrm{K}$ and $\sim 1475 \mathrm{ppm}$ Na reside in the Martian core. The same calculation for Vesta yields a minimum of $\sim 260$ ppm K and $\sim 3150$ ppm Na. Given the geochemically similar behavior of $\mathrm{Rb}$ and $\mathrm{Cs}$ to $\mathrm{K}$ and $\mathrm{Na}^{11}$, it is expected that these elements would also partition significantly into metallic cores ${ }^{11}$. Sequestration of alkalis into planetary cores can also explain the observed well-defined correlations between alkalis and incompatible, lithophile trace elements in samples from these bodies that are hard to explain by significant degassing of alkalis (Fig. S10, Supplementary Information). Alkali segregation is also consistent with a lack of post-core formation magmatic devolatilization in bulk silicate Vesta that is suggested by the $\mathrm{Zn}, \mathrm{Li}$ and $\mathrm{Cd}$ stable isotopic compositions of HED's and the $\delta \mathrm{D}$ ratios values found for most eucrites ${ }^{60-63}$.

The $\mathrm{Mn} / \mathrm{Na}$ ratios of both the Martian and Vestan mantles are supra-chondritic relative to the $\mathrm{Mn} / / \mathrm{Na}$ ratios of their inferred chondritic bulk compositions ${ }^{32,64,65}$. As Mn behave mores siderophile relative to $\mathrm{Na}$ (and K) under the experimental conditions studied here (Tables S3, S4), these ratios require that some Na must have been lost during their early evolution. In addition, Tian et al. ${ }^{66}$ recently reported new heavy K isotopic measurements of HED meteorites, which also suggest some amount of $\mathrm{K}$ must have been lost before or during Vesta's differentiation. This agrees with the heavy $\mathrm{Rb}$ stable isotopic compositions of HED's ${ }^{3}$. Alternatively, the data may imply that the Martian and Vestan building blocks were already depleted in $\mathrm{Na}$ and $\mathrm{K}$. For Vesta, an initial depletion of $\mathrm{Na}$ has been shown to be one of the requirements to produce Juvinas-like eucritic liquids from a chondritic bulk Vesta composition ${ }^{36}$. We note that this does not change the observation that significant quantities of alkali elements can partition in their cores.

In case of the Moon, it is impossible to reconcile $\mathrm{Na}$ and $\mathrm{K}$ depletions with core formation depletion, unless extremely high core formation temperatures are considered $(>3400 \mathrm{~K}$ for $\mathrm{K}$ and $>3600 \mathrm{~K}$ for $\mathrm{Na}$, the exact temperature dependent of the assumed core composition and core mass). This is due to the extreme depletions of alkalis in the lunar mantle, relative to bulk silicate Earth (BSE) ${ }^{67}$, and the S-poor nature of the lunar core ${ }^{68,69}$. This observation agrees with the observation of heavier-than-BSE K, Rb, Ga and $\mathrm{Zn}$ isotopic compositions of primitive lunar materials, consistent with their evaporative loss from Moon-forming materials ${ }^{2,3,70,71}$. It is also in agreement with the much lower $\mathrm{Mn} / \mathrm{Mg}$ and similar $\mathrm{Mn} / \mathrm{Na}$ ratios of the Moon, relative to Mars and Vesta, suggesting $\mathrm{Na}$ (and likely other alkalis) were lost in significant quantifies during the Moon-forming event ${ }^{64,65}$. Our results therefore provide additional evidence for evaporative loss of volatiles during lunar formation that support a giant impact origin of the Moon ${ }^{72-77}$. 
As illustrated by the lunar example, the point of our work is not to claim that alkali depletion through partial volatilization or incomplete condensation cannot or does not occur. In fact, some loss of alkali elements is required from the $\mathrm{K}$ and $\mathrm{Rb}$ isotopic signatures of HED's ${ }^{66}$ and the eucrites Juvinas and Stannern ${ }^{3}$ and $\delta^{37} \mathrm{Cl}$ isotopic signatures of eucrites ${ }^{78}$ in the case of Vesta, and from $\mathrm{Mn} / \mathrm{Na}$ ratios in the case of the Moon, Mars and Vesta $^{64,65}$. But our work does indicate that assigning all mantle depletion of alkalis to partial volatilization or incomplete condensation is incorrect under a wide range of planetary formation and core-mantle differentiation conditions. Finally, we note that the heat from radioactive decay of the inferred substantial concentrations of $\mathrm{K}$ in the cores of Mars and Vesta may provide a feasible mechanism to generate and sustain the enigmatic early core dynamos in these bodies, suggested by the magnetization of their oldest rocks ${ }^{79}$.

\section{Methods}

High pressure experiments. Experiments were performed at $1683 \mathrm{~K}$ to $1883 \mathrm{~K}$ at $1 \mathrm{GPa}$ in a Bristol-type end-loaded piston-cylinder press at the Vrije Universiteit Amsterdam. Metal-silicate and sulfide-silicate partitioning experiments were performed using graphite capsules, which were placed in platinum (Pt) capsules. The Pt capsules were then crimped and welded shut in a triple junction pattern to prevent in- or exfiltration of volatile species. Capsules were placed within a half-inch diameter talc-pyrex cell assembly. Starting compositions were a synthetic analogues of a primitive basalt ${ }^{80}$ and a granitic composition ${ }^{81}$ to study the possible effects of silicate melt composition (Supplementary Table 1). Metal mixtures consisted of pure $\mathrm{Fe}, \mathrm{Fe}_{83} \mathrm{Si}_{17}$ or $\mathrm{FeS}$ powders. Temperature was monitored using a Type D (97\% W/3\% Re - 75\% W/25\% Re) thermocouple and Eurotherm 2404 programmable controller. The center of the samples was located in the hotspot of the assembly, $2 \mathrm{~mm}$ away from the thermocouple tip, so that sample temperatures were within $10^{\circ} \mathrm{C}$ of the thermocouple reading ${ }^{24}$. Pressure was gradually increased during heating (hot piston-in technique). Experiments were run between 15 and 160 minutes which has previously shown to be sufficient for attainment of equilibrium ${ }^{16}$. Experiments were rapidly quenched by shutting off the power to the furnace. Recovered samples were mounted in petropoxy resin, carefully dry polished to a fine using silicon carbide sandpaper plus graphite powder and subsequently analyzed using EPMA and LA-ICP-MS. Great care was taken to avoid K loss, by preventing any contact with water or oil, and by polishing as close as possible in time before EPMA analyses ${ }^{6}$.

Analytical techniques. After samples were carbon-coated, major element abundances in the silicate and metal were measured using a JEOL JXA-8800M Electron Microprobe at Utrecht University and a JEOL JXA-8900 Electron Microprobe at the University of Münster (Supplementary Tables 2 and 3). Analysis was done using an accelerating voltage of $15 \mathrm{kV}$. A $5 \mu \mathrm{m}$ sized beam was used for homogeneous phases and a $15 \mu \mathrm{m}$ diameter beam for heterogeneous phases. Metal standards for electron microprobe analyses consisted of tephroite for Mn, chalcopyrite for $\mathrm{S}$, jadeite for $\mathrm{Na}, \mathrm{KTiPO}_{5}$ for $\mathrm{K}, \mathrm{MgO}$ for $\mathrm{O}$ and pure metal standards for $\mathrm{Cr}$, Fe, Ni. Silicate analyses were calibrated with diopside for $\mathrm{Si}$ and $\mathrm{Ca}$, forsterite for $\mathrm{Mg}$, corundum for $\mathrm{Al}$, hematite for $\mathrm{Fe}$, tephroite for $\mathrm{Mn}, \mathrm{KTiPO}_{5}$ for $\mathrm{K}$, TiO for Ti, jadeite for $\mathrm{Na}$, chalcopyrite for $\mathrm{S}$ and pure metal standards for $\mathrm{Cr}$ and Ni. Oxygen was measured on the LDE1-multi-layer-crystal at Münster University. Measurements of O were optimized by discrimination of the $2^{\text {nd }}$ order $\mathrm{Na} \mathrm{K}$-alpha interference on $\mathrm{O}$ by optimizing PHA-settings, by using standards and unknowns with the same coating thickness and through the use of an Evactron plasma cleaner to remove hydrocarbons. Data was processed using the ZAF algorithm ${ }^{82}$.

Laser ablation inductively coupled plasma mass spectrometry (LA-ICP-MS) was used to quantify the abundances of K, $\mathrm{Na}$ and other elements in the metallic and silicate melt (Supplementary Tables 2 and 3 ). K and $\mathrm{Na}$ in-situ trace element concentrations were measured in high resolution mode $((\mathrm{m} / \mathrm{z}) / \Delta(\mathrm{m} / \mathrm{z})=10,000$ at $10 \%$ peak valley definition) in order to resolve polyatomic and doubly charged ion interferences (i.e. ${ }^{1} \mathrm{H}^{38} \mathrm{Ar}$ on ${ }^{39} \mathrm{~K}$ ). An $193 \mathrm{~nm}$ excimer laser (Analyte G2, Photon Machines) was set to a repetition rate of $10 \mathrm{~Hz}$ at a fluence of 3-4 J/ $\mathrm{cm}^{2}$ for all analyses. Beam size ranged between 50 and $110 \mu \mathrm{m}$. Groups of about 20 samples were bracketed with three NIST 610 glass measurements which was used as external reference material for metals and silicates. Internal standard elements for silicates and for metals have been previously determined by EPMA (Supplementary Tables 2 and 3). The signal ablation time was 40 seconds for the peak and 20 seconds for the background. Washout time between individual spots was 15 seconds. Along with the unknown samples a set of well characterized reference materials was analyzed to check for precision and accuracy over the course of this study. Elemental analysis was carried out with an Element 2 mass spectrometer (ThermoFisher) at high resolution mode. Before starting analysis, the system was tuned to get stable signals and high sensitivity, as well as low oxide rates $\left({ }^{232} \mathrm{Th}^{16} \mathrm{O} /{ }^{232} \mathrm{Th}<0.1 \%\right)$ during ablation. The masses of ${ }^{23} \mathrm{Na},{ }^{29} \mathrm{Si},{ }^{39} \mathrm{~K},{ }^{43} \mathrm{Ca},{ }^{47} \mathrm{Ti},{ }^{53} \mathrm{Cr},{ }^{55} \mathrm{Mn},{ }^{60} \mathrm{Ni}$, and ${ }^{195} \mathrm{Pt}$ were measured for each spot using the e-scan (i.e. peak jumping) mode. Signals collected from LA-ICP-MS analyses were quantified using the Glitter Version 4.4.2 software. We show in the Supplementary Fig. S3 that there is excellent agreement between measured and recommended and reported $\mathrm{K}$ and $\mathrm{Na}$ abundances in virtually all reference materials that have been analyzed as unknowns during the course of this study. The abundances in both low $\mathrm{K} / \mathrm{Na}$ and high $\mathrm{K} / \mathrm{Na}$ reference materials suggest that the approach used here can be used to adequately quantify $\mathrm{K}$ and $\mathrm{Na}$ abundances in the experiments reported here.

Data availability. The datasets generated during and/or analysed during the current study are available from the corresponding author on reasonable request.

\section{References}

1. Humayun, M. \& Clayton, R. N. Potassium isotope cosmochemistry: Genetic implications of volatile element depletion. Geochim. Cosmochim. Acta 59, 2131-2148 (1995).

2. Wang, K. \& Jacobsen, S. B. Potassium isotopic evidence for a high-energy giant impact origin of the Moon. Nature 538, 487-490 (2016). 
3. Pringle, E. A. \& Moynier, F. Rubidium isotopic composition of the Earth, meteorites, and the Moon: Evidence for the origin of volatile loss during planetary accretion. Earth Planet. Sci. Lett. 473, 62-70 (2017).

4. Nakajima, M. \& Stevenson, D. J. Inefficient volatile loss from the Moon-forming disk: Reconciling the giant impact hypothesis and a wet Moon. Earth Planet. Sci. Lett. 487, 117-126 (2018).

5. Day, J. M. D. \& Moynier, F. Evaporative fractionation of volatile stable isotopes and their bearing on the origin of the Moon. Philos. Trans. A. Math. Phys. Eng. Sci. 372, 20130259 (2014).

6. Murthy, V. R., van Westrenen, W. \& Fei, Y. Experimental evidence that potassium is a substantial radioactive heat source in planetary cores. Nature 423, 163-165 (2003).

7. Wasserburg, G. J., MacDonald, G. J. F., Hoyle, F. \& Fowler, W. A. Relative Contributions of Uranium, Thorium, and Potassium to Heat Production in the Earth. Science 143, 465-467 (1964).

8. Williams, J. P. \& Nimmo, F. Thermal evolution of the Martian core: Implications for an early dynamo. Geology 32, 97-100 (2004).

9. Nimmo, F., Price, G. D., Brodholt, J. \& Gubbins, D. The influence of potassium on core and geodynamo evolution. Geophys. J. Int. 156, 363-376 (2004).

10. Lodders, K. Alkali elements in the Earth's core: Evidence from enstatite meteorites. Meteorit. Planet. Sci. 30, 91-101 (1995).

11. Mills, N. M., Agee, C. B. \& Draper, D. S. Metal-silicate partitioning of cesium: Implications for core formation. Geochim. Cosmochim. Acta 71, 4066-4081 (2007).

12. Bouhifd, M. A. et al. Potassium partitioning into molten iron alloys at high-pressure: Implications for Earth's core. Phys. Earth Planet. Inter. 160, 22-33 (2007).

13. Blanchard, I., Badro, J., Siebert, J. \& Ryerson, F. J. Composition of the core from gallium metal-silicate partitioning experiments. Earth Planet. Sci. Lett. 427, 191-201 (2015).

14. Blanchard, I., Siebert, J., Borensztajn, S. \& Badro, J. The solubility of heat-producing elements in Earth's core. Geochemical Perspect. Lett. 1-5, https://doi.org/10.7185/geochemlet.1737 (2017).

15. Hirao, N. et al. Partitioning of potassium between iron and silicate at the core-mantle boundary. Geophys. Res. Lett. 33, L08303 (2006).

16. Corgne, A., Keshav, S., Fei, Y. \& McDonough, W. F. How much potassium is in the Earth's core? New insights from partitioning experiments. Earth Planet. Sci. Lett. 256, 567-576 (2007).

17. Gessmann, C. K. \& Wood, B. J. Potassium in the Earth's core? Earth Planet. Sci. Lett. 200, 63-78 (2002)

18. Wade, J. \& Wood, B. J. Core formation and the oxidation state of the Earth. Earth Planet. Sci. Lett. 236, 78-95 (2005).

19. Wood, B. J. \& Wade, J. Activities and volatilities of trace components in silicate melts: A novel use of metal-silicate partitioning data. Contrib. to Mineral. Petrol. 166, 911-921 (2013).

20. Lee, J. H. \& Morita, K. Evaluation of Surface Tension and Adsorption for Liquid Fe-S Alloys. ISIJ Int. 42, 588-594 (2002).

21. Righter, K. et al. Distribution of Sb, As, Ge, and In between metal and silicate during accretion and core formation in the Earth. Geochim. Cosmochim. Acta 198, 1-16 (2017).

22. Tuff, J., Wood, B. J. \& Wade, J. The effect of Si on metal-silicate partitioning of siderophile elements and implications for the conditions of core formation. Geochim. Cosmochim. Acta 75, 673-690 (2011).

23. Wang, Z., Laurenz, V., Petitgirard, S. \& Becker, H. Earth's moderately volatile element composition may not be chondritic: Evidence from In, Cd and Zn. Earth Planet. Sci. Lett. 435, 136-146 (2016).

24. Wood, B. J., Kiseeva, E. S. \& Mirolo, F. J. Accretion and core formation: The effects of sulfur on metal-silicate partition coefficients. Geochim. Cosmochim. Acta 145, 248-267 (2014).

25. Wood, B. J. \& Kiseeva, E. S. Trace element partitioning into sulfide: How lithophile elements become chalcophile and vice versa. Am. Mineral. 100, 2371-2379 (2015).

26. Kiseeva, E. S. \& Wood, B. J. A simple model for chalcophile element partitioning between sulphide and silicate liquids with geochemical applications. Earth Planet. Sci. Lett. 383, 68-81 (2013).

27. Kiseeva, E. S. \& Wood, B. J. The effects of composition and temperature on chalcophile and lithophile element partitioning into magmatic sulphides. Earth Planet. Sci. Lett. 424, 280-294 (2015).

28. Mysen, B. O., Virgo, D. \& Seifert, F. A. The structure of silicate melts: Implications for chemical and physical properties of natural magma. Reviews of Geophysics 20, 353-383 (1982).

29. Borisov, A. A. Influence of $\mathrm{SiO} 2$ and Al2O3 on the activity coefficients of alkalis in melts: An experimental study. Petrology 17, 579 (2009).

30. Steenstra, E. S., Knibbe, J. S., Rai, N. \& van Westrenen, W. Constraints on core formation in Vesta from metal-silicate partitioning of siderophile elements. Geochim. Cosmochim. Acta 177, 48-61 (2016).

31. Sanloup, C., Jambon, A. \& Gillet, P. A simple chondritic model of Mars. Phys. Earth Planet. Inter. 112, $43-54$ (1999).

32. Taylor, G. J. The bulk composition of Mars. Chemie der Erde - Geochemistry 73, 401-420 (2013).

33. Lodders, K. \& Fegley, B. An Oxygen Isotope Model for the Composition of Mars. Icarus 126, 373-394 (1997).

34. Khan, A. \& Connolly, J. A. D. Constraining the composition and thermal state of Mars from inversion of geophysical data. J. Geophys. Res. E Planets 113, E07003 (2008).

35. Wang, Z. \& Becker, H. Chalcophile elements in Martian meteorites indicate low sulfur content in the Martian interior and a volatile element-depleted late veneer. Earth Planet. Sci. Lett. 463, 56-68 (2017).

36. Toplis, M. J. et al. Chondritic models of 4 Vesta: Implications for geochemical and geophysical properties. Meteorit. Planet. Sci. 48, $2300-2315$ (2013).

37. Kitts, K. \& Lodders, K. Survey and evaluation of eucrite bulk composititons. Meteorit. Planet. Sci. 33, A197-A213 (1998).

38. Lodders, K. A survey of shergottite, nakhlite and chassigny meteorites whole-rock compositions. Meteorit. Planet. Sci. 33, A183-A190 (1998)

39. Stewart, A. J., Schmidt, M. W., van Westrenen, W. \& Liebske, C. Mars: A New Core-Crystallization Regime. Science 316, 1323-1325 (2007).

40. Fu, R. R. et al. An Ancient Core Dynamo in Asteroid Vesta. Science 338, 238-241 (2012).

41. Righter, K. et al. Highly siderophile element (HSE) abundances in the mantle of Mars are due to core formation at high pressure and temperature. Meteorit. Planet. Sci. 50, 604-631 (2015).

42. Rai, N. \& Van Westrenen, W. Core-mantle differentiation in Mars. J. Geophys. Res. E Planets 118, 1195-1203 (2013).

43. Rivoldini, A., Van Hoolst, T., Verhoeven, O., Mocquet, A. \& Dehant, V. Geodesy constraints on the interior structure and composition of Mars. Icarus 213, 451-472 (2011).

44. Elkins-Tanton, L. T., Hess, P. C. \& Parmentier, E. M. Possible formation of ancient crust on Mars through magma ocean processes. J. Geophys. Res. E Planets 110, 1-11 (2005).

45. Dauphas, N. \& Pourmand, A. Hf-W-Th evidence for rapid growth of Mars and its status as a planetary embryo. Nature 473, 489-492 (2011).

46. Tang, H. \& Dauphas, N. 60Fe-60Ni chronology of core formation in Mars. Earth Planet. Sci. Lett. 390, 264-274 (2014).

47. Formisano, M. et al. The heating history of Vesta and the onset of differentiation. Meteorit. Planet. Sci. 48, 2316-2332 (2013).

48. Ricard, Y., Bercovici, D. \& Albarède, F. Thermal evolution of planetesimals during accretion. Icarus 285, 103-117 (2017).

49. Larsen, K. K., Schiller, M. \& Bizzarro, M. Accretion timescales and style of asteroidal differentiation in an 26Al-poor protoplanetary disk. Geochim. Cosmochim. Acta 176, 295-315 (2016). 
50. Greenwood, R. C. et al. The oxygen isotope composition of diogenites: Evidence for early global melting on a single, compositionally diverse, HED parent body. Earth Planet. Sci. Lett. 390, 165-174 (2014).

51. Greenwood, R. C., Franchi, I. A., Jambon, A. \& Buchanan, P. C. Widespread magma oceans on asteroidal bodies in the early Solar System. Nature 435, 916-918 (2005).

52. Righter, K. \& Drake, M. J. A magma ocean on Vesta: Core formation and petrogenesis of eucrites and diogenites. Meteorit. Planet. Sci. 32, 929-944 (1997)

53. Elardo, S. M. \& Shahar, A. Non-chondritic iron isotope ratios in planetary mantles as a result of core formation. Nat. Geosci. 10, 317-321 (2017)

54. Boyet, M. 142Nd Evidence for Early (\&gt;4.53 Ga) Global Differentiation of the Silicate Earth. Science 309, 576-581 (2005)

55. Simon, J. I. \& DePaolo, D. J. Stable calcium isotopic composition of meteorites and rocky planets. Earth Planet. Sci. Lett. 289, 457-466 (2010)

56. Moynier, F., Agranier, A., Hezel, D. C. \& Bouvier, A. Sr stable isotope composition of Earth, the Moon, Mars, Vesta and meteorites. Earth Planet. Sci. Lett. 300, 359-366 (2010).

57. Wang, K. et al. Iron isotope fractionation in planetary crusts. Geochim. Cosmochim. Acta 89, 31-45 (2012).

58. Righter, K. \& Chabot, N. L. Moderately and slightly siderophile element constraints on the depth and extent of melting in early Mars. Meteorit. Planet. Sci. 46, 157-176 (2011).

59. Yang, S. et al. Siderophile and chalcophile element abundances in shergottites: Implications for Martian core formation. Meteorit. Planet. Sci. 50, 691-714 (2015).

60. Paniello, R. C. et al. Zinc isotopes in HEDs: Clues to the formation of 4-Vesta, and the unique composition of Pecora Escarpment 82502. Geochim. Cosmochim. Acta 86, 76-87 (2012).

61. Magna, T., Šimčíková, M. \& Moynier, F. Lithium systematics in howardite-eucrite-diogenite meteorites: Implications for crustmantle evolution of planetary embryos. Geochim. Cosmochim. Acta 125, 131-145 (2014).

62. Wombacher, F., Rehkämper, M., Mezger, K., Bischoff, A. \& Münker, C. Cadmium stable isotope cosmochemistry. Geochim. Cosmochim. Acta 72, 646-667 (2008).

63. Barrett, T. J. et al. The abundance and isotopic composition of water in eucrites. Meteorit. Planet. Sci. 51, 1110-1124 (2016).

64. O'Neill, H. S. \& Palme, H. Collisional erosion and the non-chondritic composition of the terrestrial planets. Philos. Trans. R. Soc. A Math. Phys. Eng. Sci. 366, 4205-4238 (2008).

65. Siebert, J. et al. Chondritic Mn/Na ratio and limited post-nebular volatile loss of the Earth. Earth Planet. Sci. Lett. 485, 130-139 (2018).

66. Tian, Z. et al. Potassium Isotope Differences among Chondrites, Earth, Moon, Mars, and 4-Vesta - Implications on the Planet Accretion Mechanisms. Lunar Planet. Sci. Conf. 49th, 1276 (2018).

67. Hauri, E. H., Saal, A. E., Rutherford, M. J. \& Van Orman, J. A. Water in the moon's interior: Truth and consequences. Earth Planet. Sci. Lett. 409, 252-264 (2015).

68. Steenstra, E. S., Lin, Y., Rai, N., Jansen, M. \& van Westrenen, W. Carbon as the dominant light element in the lunar core. Am. Mineral. 102, 92-97 (2017).

69. Righter, K. et al. Phase equilibria of a low $S$ and $C$ lunar core: Implications for an early lunar dynamo and physical state of the current core. Earth Planet. Sci. Lett. 463, 323-332 (2017).

70. Paniello, R. C., Day, J. M. D. \& Moynier, F. Zinc isotopic evidence for the origin of the Moon. Nature 490, 376-379 (2012).

71. Kato, C. \& Moynier, F. Gallium isotopic evidence for extensive volatile loss from the Moon during its formation. Sci. Adv. 3, e1700571 (2017).

72. Cuk, M., Hamilton, D. P., Lock, S. J. \& Stewart, S. T. Tidal evolution of the Moon from a high-obliquity, high-angular-momentum Earth. Nature 539, 402-406 (2016).

73. Canup, R. M. Forming a Moon with an Earth-like Composition via a Giant Impact. Science 338, 1052-1055 (2012).

74. Boyce, J. W. et al. The chlorine isotope fingerprint of the lunar magma ocean. Sci. Adv. 1, e1500380-e1500380 (2015).

75. Kato, C., Moynier, F., Valdes, M. C., Dhaliwal, J. K. \& Day, J. M. D. Extensive volatile loss during formation and differentiation of theMoon. Nat. Comm. 6 (2015).

76. Day, J. M. D., Moynier, F. \& Shearer, C. K. Late-stage magmatic outgassing from a volatile-depletedMoon. Proc. Natl. Acad. Sci. 114, 9547-9551 (2017).

77. Norris, C. A. \& Wood, B. J. Earth's volatile contents established by melting and vaporization. Nature 549, 507-510 (2017).

78. Sarafian, A. R., John, T., Roszjar, J. \& Whitehouse, M. J. Chlorine and hydrogen degassing in Vesta's magma ocean. Earth Planet. Sci. Lett. 459, 311-319 (2017)

79. Roberts, J. H., Rivkin, A. S. \& Chabot, N. L. Thermal challenges for recording an ancient core dynamo on vesta. In Workshop on Planetesimal Formation and Differentiation 8033 (2013).

80. Delano, J. W. Pristine lunar glasses: Criteria, data, and implications. J. Geophys. Res. Solid Earth 91, 201-213 (1986).

81. Warren, P. H., Taylor, G. J., Keil, K., Shirley, D. N. \& Wasson, J. T. Petrology and chemistry of two 'large' granite clasts from the moon. Earth Planet. Sci. Lett. 64, 175-185 (1983).

82. Reed, S. J. B. Electron Microprobe Analysis and Scanning Electron Microscopy in Geology. Electron Microprobe Anal. Scanning Electron Microsc. Geol. 19, https://doi.org/10.1017/CBO9780511610561 (2005).

83. Ruzicka, A., Snyder, G. a. \& Taylor, L. a. Vesta as the howardite, eucrite and diogenite parent body: Implications for the size of a core and for large-scale differentiation. Meteorit. Planet. Sci. 32, 825-840 (1997).

\section{Acknowledgements}

This work was supported by a Netherlands Organization for Scientific Research (N.W.O.) Vici award to W.v.W. and was partially funded by SFB TRR-170 (No. 33). We thank three anonymous reviewers for their constructive comments that greatly improved the quality and clarity of this manuscript.

\section{Author Contributions}

E.S.S. and W.v.W. designed the project. E.S.S. and N.A. performed the experiments. E.S.S., N.A., J.B., S.K. and S.M. performed sample analyses. All authors discussed the results. E.S.S. and W.v.W. wrote the paper with input from all authors. Additional details on experimental and numerical methods are reported in the Supplementary Materials file.

\section{Additional Information}

Supplementary information accompanies this paper at https://doi.org/10.1038/s41598-018-25505-6.

Competing Interests: The authors declare no competing interests.

Publisher's note: Springer Nature remains neutral with regard to jurisdictional claims in published maps and institutional affiliations. 
(i) Open Access This article is licensed under a Creative Commons Attribution 4.0 International License, which permits use, sharing, adaptation, distribution and reproduction in any medium or format, as long as you give appropriate credit to the original author(s) and the source, provide a link to the Creative Commons license, and indicate if changes were made. The images or other third party material in this article are included in the article's Creative Commons license, unless indicated otherwise in a credit line to the material. If material is not included in the article's Creative Commons license and your intended use is not permitted by statutory regulation or exceeds the permitted use, you will need to obtain permission directly from the copyright holder. To view a copy of this license, visit http://creativecommons.org/licenses/by/4.0/.

(C) The Author(s) 2018 